\title{
Sujeito, sociedade e linguagem \\ Uma reflexão sobre as bases teóricas da pesquisa com narrativas biográficas
}

\author{
Subject, society and language \\ A reflection on the theoretical grounds of biographic \\ narratives research
}

Marcos Fanton*

\begin{abstract}
Resumo: O foco deste artigo é o esclarecimento de alguns dos principais conceitos utilizados pelo método das narrativas biográficas. Ainda que esta metodologia seja utilizada amplamente, as suas bases teóricas ainda não parecem ter sido sistematicamente elaboradas. Nesse sentido, os objetivos deste artigo são os seguintes: [i] desenvolver o método de entrevista narrativa e o método de análise de narrativas biográficas criado por Fritz Schütze; [ii] esclarecer algumas das teses teóricas que tal autor assume, no que diz respeito à tarefa da sociologia e de seu(s) objeto(s) de estudo, a partir dos conceitos de sujeito, sociedade e linguagem; [iii] explorar as influências da matriz teórica da sociologia fenomenológica de Alfred Schutz na metodologia de Schütze e realizar uma comparação entre ambas. Concluimos afirmando que a sociologia fenomenológica não pode ser considerada a única matriz teórica que fundamenta a metodologia de Schütze, o que aponta para novos questionamentos.
\end{abstract}

Palavras-chave: Filosofia da sociologia, Sociologia fenomenológica, Narrativas biográficas, linguagem

Abstract: The aim of this paper is the clarification of some key concepts of the methodology of biographical narratives. Despite of the fact that this methodology is widely used, its theoretical underpinnings not yet appear to have been systematically compiled. Accordingly, the objectives of this paper are as follows: [i] develop the method of narrative interview and the method of analysis of biographical narratives created by Fritz Schütze; [ii] clarify some of the theoretical points that this author assumes (as the task of sociology and its object of study) through the concepts of self, society and language; and [iii] explore the influences of the theoretical framework of the phenomenological sociology of Alfred Schutz and compare both authors. Its conclusion is the statement that the phenomenological sociology cannot be considered the only

* Doutorando em filosofia na PUCRS. E-mail: <fanton.marcos@gmail.com>.

\begin{tabular}{|c|c|c|c|c|c|}
\hline Civitas & Porto Alegre & v. 11 & n. 3 & p. 529-543 & set.-dez. 2011 \\
\hline
\end{tabular}


theoretical framework that underlies Schütze's methodology, which points out to new questions.

Keywords: Philosophy of sociology, phenomenological sociology, biographic narrative, language

O crescente uso de narrativas na pesquisa sociológica é comumente visto como um sintoma da insatisfação dos resultados trazidos pelos métodos quantitativos ou pelos métodos qualitativos que tendem a padronizar as respostas dos indivíduos entrevistados. Estes métodos, argumentam os teóricos a favor das narrativas, frequentemente menosprezam o caso único e complexo do sujeito que está imerso na realidade social, deixam de lado as trajetórias biográficas singulares ou, ainda, esquecem-se do esquema conceitual construído de maneira significativa pelos indivíduos (Elliot, 2005, p. 205). Por outro lado, a análise de narrativas não enfrenta menos críticas ou dificuldades por sua especificidade. Critica-se o seu suposto isolamento das situações sociais cotidianas, deixando o sociólogo à deriva de interpretações arbitrárias e sem a possibilidade de compreender o papel das estruturas (sociais) na vida dos seres humanos (Elias, 1997, p. 72).

Em um primeiro momento, podemos perceber que tal debate, que está longe de encontrar um ponto pacífico entre os sociólogos, não apenas versa sobre os métodos utilizados na pesquisa, como também sobre quais são os dados empíricos cientificamente válidos na sociologia. Além disso, este debate provoca-nos a interrogar sobre a concepção de sociologia que está na base de tais modos de pesquisa. Afinal, estamos realmente falando sobre a mesma coisa?

Gostaria de esclarecer, nesse sentido, que o objetivo deste artigo é esclarecer alguns conceitos utilizados pelo método das narrativas (especificamente, das narrativas biográficas) e o nível teórico no qual esta metodologia opera. Ao trabalharmos com narrativas, um tipo específico de pesquisa qualitativa, que noções teóricas precisamos levar em consideração? Qual a concepção de sociologia que pressupomos? Como são formados os dados científicos a partir desta concepção?

Dentro deste quadro de questionamentos, os objetivos deste artigo são os seguintes: [i] desenvolver o método de entrevista narrativa e o método de análise de narrativas biográficas criado por Fritz Schütze; [ii] esclarecer algumas das teses teóricas que tal autor assume, no que diz respeito à tarefa da sociologia e de seu(s) objeto(s) de estudo, a partir dos conceitos de sujeito, sociedade 
e linguagem; [iii] explorar as influências da matriz teórica da sociologia fenomenológica de Alfred Schutz na metodologia de Schütze e realizar uma comparação entre ambas. Por 'matriz teórica sociológica' entenderemos, de modo indeterminado, uma teoria sociológica capaz de explicar a realidade social e as interações sociais entre os indivíduos.

\section{Fritz Schütze e a pesquisa de narrativas biográficas}

A fim de não nos prendermos a conceitos vagos ou intuitivos logo no início, é conveniente delimitarmos o conceito de narração, ainda que sem o vincular a uma matriz teórica específica. Tal como é encontrado em um dos manuais de pesquisa social, a noção de 'narrativa' pode ser entendida como os "discursos [dos indivíduos] com uma ordem sequencial definida que, nesse sentido, oferecem compreensões sobre o mundo e/ou experiências dos indivíduos sobre este" (Hinchman; Hinchman apud Elliot, 2005, p. 3).

Desta definição, compreendemos que toda narração possui, basicamente, cinco características principais: [a] uma característica temporal: a narrativa é a representação de eventos passados a partir de uma perspectiva atual; [b] uma característica social: a situação na qual ocorre a entrevista é uma situação social, que irá influenciar o modo de narração do indivíduo. Ou seja, o discurso deste é um discurso para uma audiência específica; [c] uma característica significativa: a narrativa expressa o significado dado pelos indivíduos à suas experiências e situações passadas, assim como da sua vida (biografia) como um todo; [d] uma característica subjetiva: a narrativa é sempre a expressão da perspectiva de um indivíduo cuja biografia é única e singular; [e] uma característica linguística: a narração é realizada a partir da linguagem cotidiana do indivíduo, quer dizer, da linguagem que lhe é mais familiar e rotineira.

Um dos modos de se utilizar este tipo de discurso é a pesquisa de narrativas da própria biografia do entrevistado (as narrativas biográficas), elaborada pela primeira vez nos anos 1920, pela Universidade de Chicago, e estabelecida como um método de pesquisa no final da década de 1970, com os trabalhos do alemão Martin Kohli e do francês Daniel Bertaux. A pesquisa biográfica formou-se com a motivação de investigar o contexto no qual a realidade social enquanto tal é construída, isto é, pela compreensão das experiências e das ações de cada indivíduo em particular e pela interação social com outros indivíduos. Somente após a realização desta etapa, agora entendida como fundamental, passa-se à generalização, a fim de verificar a validade científica da pesquisa.

Um dos autores que desenvolveu de maneira sistemática o método de entrevista e de análise dos dados empíricos da narrativa biográfica foi o sociólogo 
alemão Fritz Schütze. O emprego de uma metodologia específica para suas pesquisas tem como objetivo principal permitir que o indivíduo entrevistado realize um "trabalho biográfico" [biographical work], isto é, um tipo de trabalho que consiste em "moldar" a própria identidade pessoal referindo-se a si mesmo através da narração nas mais diversas situações, o que inclui, por exemplo, falar sobre a compreensão que se tem de si mesmo como uma identidade única e singular, que está em desenvolvimento ou em declínio; sobre o discernimento dos impasses ou dos impedimentos para se desenvolver; sobre a recordação de experiências passadas (traumáticas ou prósperas); sobre a reflexão de novas ou diferenciadas maneiras de se autocompreender e se desenvolver; sobre a decisão dos passos futuros e dos planos de vida (Schütze, 2010a, p. 6).

Em alguma medida, explícita ou implicitamente, todos nós realizamos uma atividade deste tipo: nós falamos sobre nossa vida atual e nossos planos para o futuro, contamos a nossos amigos, vizinhos ou conhecidos sobre experiências que vivemos, relembramos diversos episódios ou modos de se autocompreender o passado, etc. É, então, esta atividade narrativa cotidiana que Schütze procura transformar em autênticos data para as pesquisas na sociologia, a partir de um método sistemático que controle sua produção.

O seu método de entrevistas é constituído por etapas ordenadas, todas direcionadas à criação de uma situação na qual o entrevistado sinta-se à vontade e estimulado para narrar sua própria vida ${ }^{1}$. Portanto, a intenção deste tipo de entrevista é, basicamente, motivar o engajamento do indivíduo na produção do trabalho biográfico espontâneo. Para isso, a pergunta inicial realizada pelo pesquisador deve ser extremamente ampla e não envolver quaisquer conceitos ou expressões linguísticas alheias ao indivíduo entrevistado. Assim, a formulação de questões guia-se pelo vocabulário previamente utilizado por este último, deixando-se de lado a rede conceitual técnica do pesquisador. Como exemplo de pergunta inicial, temos a seguinte, elaborada pela socióloga Gabriele Rosenthal:

Por favor, conte-me a história de sua família e a sua história de vida pessoal. Eu estou interessado em toda sua vida. Qualquer coisa que lhe ocorre. Você tem quanto tempo você quiser. Eu não lhe perguntarei qualquer questão por ora. Eu farei apenas algumas anotações sobre aquilo que eu gostaria de perguntar para você mais tarde; se nós não tivermos tempo suficiente hoje, talvez em uma segunda entrevista (Rosenthal, 2004, p. 51).

\footnotetext{
Não é de nosso interesse explicar nem todos os procedimentos da entrevista narrativa nem todas as etapas da análise de narrativas. Para tanto, ver Rosenthal, 2004; Weller, 2010; Jovchelovitc and Bauer, 2003.
} 
A utilização deste procedimento metodológico, segundo Schütze, está baseada em duas teses fundamentais: [1] a realidade social é experienciada significativamente por indivíduos com histórias biográficas únicas; e [2] esta mesma realidade social produzida é mantida, suportada, criticada, destruída ou modificada por estes mesmos indivíduos, a partir do desenvolvimento e modificação de suas identidades biográficas. Ambas as teses estão compreendidas na tese mais ampla de que a realidade social consiste, em um nível fundamental, de processos, e não de estruturas sociais fixas, tendo em vista o modo de sua produção e de sua constante modificação (Schütze, 2010 b, p. 2). Como podemos perceber, esta tese diz respeito ao estatuto teórico do objeto sociológico enquanto tal, ainda que não tenhamos claro o significado das expressões 'processo social' e 'realidade social' nos textos mencionados de Schütze.

Já o cuidado em motivar o entrevistado a utilizar, principalmente, a narração como a forma linguística do trabalho biográfico leva-nos a discutir uma tese sobre a relação entre experiência e linguagem. Schütze admite que a narração das experiências e das situações (cotidianas ou episódicas) é a forma de linguagem que mais se aproxima das experiências e situações tal como foram vividas significativamente pelo indivíduo que as narra, além de expressar a construção biográfica global do indivíduo. Este não é solicitado, na entrevista, a dar explicações sobre suas ações ou desejos, pois ele deve, simplesmente, narrar episódios de sua vida, revelando, através do vocabulário cotidiano, o significado das experiências vividas por ele mesmo. Desse modo, a narração biográfica é sempre a explicação das experiências vividas no passado tal como elas são compreendidas pelo indivíduo em sua situação biográfica atual.

Já para poder interpretar cientificamente determinado texto narrativo, pois tais entrevistas tornam-se dados empíricos a partir de sua transcrição, Schütze desenvolveu também um método de análise das narrativas biográficas. Tendo em vista, porém, que o autor estava preocupado menos em realizar conceitualizações precisas e sistemáticas sobre as noções envolvidas neste método do que em fazê-lo funcionar, esta parte do artigo deter-se-á em delimitar os conceitos desenvolvidos pelo próprio Schütze. O trabalho de um aprofundamento da matriz teórica utilizada será concretizado na segunda parte deste trabalho.

Como o sociólogo possui um método específico para a análise dos dados empíricos, ele, certamente, não pode interpretar os enunciados de uma narrativa biográfica em seu sentido literal, do mesmo modo que ele ouve, por exemplo, os contos de seus avôs, de seus pais ou mesmo de seus amigos. Tais enunciados não são ouvidos como "reflexos" da realidade. Por isso, para 
Schütze, a tarefa do sociólogo é refratar pragmaticamente o texto narrativo, o que significa, no nível metodológico, que as

formulações verbais ocorrentes deveriam ser analiticamente relacionadas aos seus contextos de experiências anteriores, aos seus contextos de produção e uso, assim como aos seus contextos de aplicação posterior, de função social e de estrutura significativa global (de biografia ou de ação). (Schütze, 2010a, p. 14)

O que Schütze quer dizer com esta estranha e metafórica expressão? Ele quer designar um método sociológico de análise de dados que restitua cada enunciado do entrevistado (por isso, que realize uma refração) ao tipo e contexto de ação expressa por ele (por isso, pragmática, no sentido de "ação", "atividade") (ibid.). Ou seja, este método tem o objetivo de explicar as funções de tais enunciados dentro dos quadros sociais que exercem um impacto na produção de sua forma e de seu significado, como, por exemplo, as situações originais de ocorrência de determinado evento do passado; a compreensão global da biografia do indivíduo no momento do evento e suas mudanças posteriores; a situação da primeira entrevista que o indivíduo realizou; a situação comunicativa atual entre pesquisador e entrevistado, etc. (Schütze, 2010a, p.25). De modo sucinto, podemos afirmar que cada enunciado integrante da narrativa é a expressão significativa de uma experiência vivida pelo entrevistado dentro de determinado contexto social. Por exemplo, se o entrevistador diz que sofre um terrível acidente em seu trabalho em determinada época de sua vida, o pesquisador deve ter condições de interpretar a relevância que este acontecimento teve na vida do indivíduo, qual a interpretação deste (isto é, qual o significado dado ao acontecimento), o que mudou em sua vida depois disso, etc.

Desse modo, poderíamos dizer que um enunciado da narrativa biográfica somente pode ser compreendido cientificamente, isto é, constituir um dado empírico para a teoria sociológica, caso ele possa ser classificado de acordo com determinadas estruturas teóricas previamente estabelecidas pelo pesquisador. Para isso, Schütze irá utilizar-se de uma "gramática" da narrativa autobiográfica espontânea, isto é, de estruturas textuais que permitem a classificação do modo de apresentação do entrevistado e da utilização de formas típicas de linguagem, que, com isso, permitem também a interpretação do significado de suas expressões lingüísticas. ${ }^{2}$ Realizar isto seria, portanto, realizar uma refração pragmática.

2 Tal "gramática" apresentada por Schütze possui um catálogo bastante rico de procedimentos de apresentação do narrador e das formas típicas de linguagem utilizadas. Este tópico, contudo, não poderá ser tratado neste trabalho dada sua extensão. A respeito, ver Schütze, 2010a, p. 16ss. 
É importante entendermos, nesse sentido, que o pesquisador sempre interpretará o enunciado do entrevistado sob um duplo viés: como a narração de um evento ou de uma situação vivida no passado e como a expressão de uma figura biográfica global, que o indivíduo molda tendo como referência sua situação presente atual. Ou seja, o modo como são interpretadas (e, com isso, significadas) as experiências vividas pré-linguisticamente pelo indivíduo dependem da sua figura biográfica moldada na situação em que ele se encontra, ao mesmo tempo em que esta figura é moldada tendo por base suas experiências e situações vividas no passado e suas explicações já realizadas. Portanto, há uma influência mútua.

Já a interpretação do modo como o indivíduo refere-se a si mesmo ao narrar tem por base três posições epistêmicas diferentes que ele pode assumir, entendidas como "centros-do-eu" [I-origo]. São elas: [i] a posição do narrador, que constitui o sujeito engajado na realização de uma autoapresentação ordenada e racional para determinado ouvinte; [ii] a posição do portador da história, representado como o sujeito que vivenciou as experiências e situações do passado e pode ou não fazer parte da figura biográfica atual do narrador; e [iii] a posição do encarregado da biografia, que expressa as expectativas futuras do sujeito em modificar ou desenvolver sua figura biográfica. Portanto, o sujeito considerado pela entrevista narrativa é tripartite, encontrando-se, dificilmente, em harmonia ou unidade entre suas partes (Schütze, 2010a, p. 42).

Além desta perspectiva subjetiva, o entrevistado pode referir-se a si mesmo e referir suas experiências e seus planejamentos a partir de uma perspectiva externa (a sociedade). Neste caso, a análise textual revela o modo como o entrevistado interpreta o mundo, as expectativas de seus companheiros e da sociedade e como ele interage com estes. Para Schütze, a apresentação desta perspectiva segue uma linguagem sobre o padrão de expectativas institucionais, que possui princípios de ordenação normativos e procedimentais nos quais o indivíduo pode internalizá-los, realizar distanciamentos e críticas sobre eles ou aproveitá-los para desenvolver sua trajetória biográfica. Em todo caso, no entanto, esta perspectiva externa, a qual Schütze denomina realidade social, possui duas perspectivas entrelaçadas: a objetiva, que exerce restrições materiais e normativas, bem como condições favoráveis, e a subjetiva, pois o indivíduo sempre levará em consideração esta dimensão objetiva a partir de sua situação biográfica atual e de seu esquema de relevância (Schütze, 2010a, p. 22-4).

Com isso, temos, de maneira bastante sucinta, o esclarecimento da metodologia construída por Schütze e o esclarecimento dos conceitos de sujeito, sociedade e linguagem ali presentes. Tais conceitos foram escolhidos com base em sua centralidade para a sociologia e, também, para sistematizar nosso estudo, 
o que permitirá, na segunda parte do artigo, realizar uma comparação com uma das influências mais marcantes de Schütze, a sociologia fenomenológica de Alfred Schutz.

Além disso, após esta primeira parte do artigo, podemos concluir que a concepção de sociologia pressuposta por Schütze pode ser descrita da seguinte maneira: a sociologia é a disciplina que explica o significado dos processos sociais criados, compreendidos, criticados ou destruídos pelos indivíduos com base na narração das experiências e ações vividas por estes em determinada sociedade. É na linguagem narrada, portanto, que a sociologia passa a buscar os data de sua pesquisa e, dessa forma, a investigar de maneira mais detalhada e minuciosa os contextos nos quais as experiências biográficas de determinados indivíduos foram experienciadas e elaboradas significativamente e quais fatores produziram mudanças ou motivaram ações em sua trajetória de vida (Weller, 2011, p. 5).

\section{A sociologia fenomenológica de Alfred Schutz}

Nosso objetivo, agora, é compreender as principais teses de Alfred Schutz e realizar uma comparação com a concepção de sociologia de Schütze. A motivação para realizar esta tarefa encontra-se na necessidade de aprofundarmos a matriz teórica de Schütze, sem nos restringirmos a sua elaboração metodológica. Afinal, é bem sabido na literatura que as narrativas biográficas possuem uma influência bastante grande da fenomenologia. Gabriele Rosenthal, por exemplo, uma das autoras que levou adiante o projeto de Schütze, explica que sua metodologia é uma "variante estruturalista da sociologia fenomenológica do conhecimento" com influências de Oevermann, Schütze, Fischer e Gurwitsch (Rosenthal, 2004, p. 3 e 5). Assim, devemos perguntar: com toda essa inovação metodológica, a tarefa da pesquisa com narrativas biográficas ainda é semelhante à sociologia fenomenológica?

Alfred Schutz pode ser considerado como o primeiro sociólogo a aplicar sistematicamente as descobertas da fenomenologia de Husserl ao campo da sociologia. Em sua primeira grande obra, A fenomenologia do mundo social, o autor pretendeu elaborar uma "teoria do método filosoficamente fundamentada", a fim de aprofundar as análises teóricas de Max Weber. Segundo Schutz, ainda que este estivesse correto sobre o ponto de partida da sociologia - o significado subjetivo -, ele deixou uma série de pressupostos problemáticos e conceitos não devidamente delimitados em sua sociologia compreensiva. Exemplos disso são as suas definições de ação, de significado subjetivo, de indivíduo e de compreensão do significado (Schutz, 1972, p. 215ss). Schutz pretende retomar, desse modo, as noções imprecisas de significado subjetivo e de compreensão 
do significado e as reelaborar à luz da investigação fenomenológica, o que significa: "traçar as raízes dos problemas das ciências sociais diretamente aos fatos fundamentais da vida consciente" (Schutz, 1972, p. xxviii). Mais tarde, em seu trabalho As estruturas do mundo-da-vida, publicado postumamente, Schutz denominará esta tarefa de uma descrição das estruturas do mundo-davida (Schutz e Luckmann, 1973).

No fundo, Schutz questiona a própria possibilidade das ciências sociais, uma vez que elas, segundo tal concepção, devem basear-se no significado subjetivo de uma ação, o que quer dizer, no significado dado por um indivíduo, cuja biografia é singular, a uma experiência vivida por ele. Assim, se este significado é subjetivo, como é possível compreendê-lo cientificamente? E como é possível acessar esse contexto de significado subjetivo a partir de categorias objetivas, como o sistema de conhecimento objetivo das ciências sociais? (Schutz, 1953, p. 28) Para responder a tais questões satisfatoriamente, Schutz realizará uma descrição, em termos fenomenológicos, da constituição do significado na realidade social, o que nos mostra, de antemão, o abandono de qualquer concepção objetivista, naturalista ou behavorista de sociologia.

Segundo o autor, o significado não é uma qualidade presente nas experiências de per si. Ele é o resultado de uma atitude intencional do indivíduo, isto é, da reflexão deste sobre as suas experiências vividas no passado a partir de um "aqui-agora" atual (de uma situação biográfica específica) e de um esquema de referências e relevâncias válido (de um estoque de conhecimento) (Schutz, 1973, p. 15-6). Nesse sentido, a observação comportamental não pode ser considerada um método adequado para a sociologia, tendo em vista, por exemplo, que o simples fato de alguém estar bravo não nos mostra o seu motivo ou o que este estado afetivo significa para ele (Schutz, 1972, p. 26). Por isso, Schutz afirmará que é sempre o ator de determinada ação, e ninguém mais, quem tem a última palavra a respeito do significado de sua ação, do modo como ela é interpretada e qual a relevância para a sua biografia (Schutz, 1989, p.4). Isto faz com que a sociologia não só se atenha ao significado subjetivo como também adote um modo diferente de interpretação dos fenômenos sociais, já que o intérprete tem apenas um acesso mediato ao significado das ações.

No entanto, subjacente a esta reflexão acerca das experiências e ações, encontra-se aquilo que é a condição de possibilidade para esta atitude: o mundoda-vida cotidiano. Este é a realidade fundamental dos indivíduos normais e adultos, caracterizada por sua autoevidência e familiaridade. Andamos de bicicleta, encontramos um amigo, calculamos a conta das compras do mercado, sentamos em uma cadeira e assistimos televisão: todas essas são ações que não perguntamos o que iremos fazer ou o que é aquilo que estamos fazendo ("o 
que é isto, a bicicleta?", "como ligo esta televisão?", etc.), porque já estamos familiarizados em fazê-las. Todas estas ações já nos foram, previamente, explicadas ou realizadas por nossos pais, amigos ou outros indivíduos, e, com isso, sedimentadas em nosso estoque de conhecimento, que dá unidade e serve de referência para minha explicação sobre o mundo (Schutz e Luckmann, 1973, p. 7). Por 'estoque de conhecimento', Schutz entende uma totalidade de explicações sobre as experiências e ações vividas pelo indivíduo, que é sempre sedimentada e condicionada biograficamente (Schutz e Luckmann, 1973, p. 14).

Assim, somente as experiências novas ou anormais, nas quais não encontramos explicações neste estoque, requisitarão uma atitude de questionamento sobre ela mesma e sobre o mundo, mas apenas até conseguirmos realizá-la. Não realizamos, por isso, um escrutínio do objeto guarda-chuva, por exemplo, para o utilizar diante de uma chuva torrencial; nós simplesmente o utilizamos. Porém, se ele estiver quebrado ou possuir um mecanismo diferente de abertura, realizaremos um questionamento apenas até conseguirmos abrilo e nos protegermos da chuva. Portanto, nossa atitude cotidiana natural é sempre determinada por esta limitação de observações, pois temos que agir, que realizar nossos planos de vida. Aqui, Schutz emprega o termo 'motivo pragmático': uma situação cotidiana é questionada apenas na medida em que ela não nos permite lidar de maneira familiar com nossos planos de vida ou nossas ações; caso contrário, ela permanecerá autoevidente. Devido a este motivo pragmático, Schutz dirá, também, que o mundo-da-vida é o mundo da prática humana (Schutz, 1989, p. 1).

Como foi dito anteriormente, o estoque de conhecimento de cada indivíduo é determinado biograficamente (ou historicamente), pois ele é o "produto" das experiências vividas, das explicações e dos questionamentos que o indivíduo realizou durante sua vida e, ainda, das suas escolhas entre determinadas ações. Nesse sentido, cada estoque de conhecimento pode ser considerado único em sua articulação biográfica, possuindo sempre um "componente privado" - o que não deixa de evidenciar também o seu limite (Schutz e Luckmann, 1973, p. 112). Nesta articulação biográfica singular, constitui-se, portanto, para cada indivíduo, um esquema de relevância e de tipicidade, como parte constituinte de seu estoque de conhecimento, isto é, um guia seletivo na interpretação de si mesmo e do mundo. Ao observarmos determinados eventos, fatos ou ações de outros indivíduos, nós sempre teremos determinados elementos que nos serão mais familiares. Devido a isto, a nossa interpretação da realidade é sempre parcial, pois ela é realizada a partir de nossa história biográfica e nossa situação atual (Schutz, 1953, p. 3). 
O conceito que Schutz emprega para se referir a esta familiaridade que temos com determinados objetos, situações ou outros indivíduos que nos são "similares" (mas não idênticos) é o de tipo. Tomemos o exemplo do objeto guarda-chuva: nós não temos familiaridade apenas com um guarda-chuva ("aquele ali, que está no armário da sala"), mas com todos os outros objetos que forem "similares" a este guarda-chuva e servirem para a mesma função. Assim, os objetos ou as situações similares são reunidos, nas palavras de sociólogo alemão, em “um contexto-de-significado 'estabelecido' nas experiências do mundo-da-vida” (Schutz e Luckmann, 1973, p. 230). Portanto, um tipo é tudo aquilo que já se tornou uma espécie de padrão em nossa vida cotidiana e é dado por óbvio, como, por exemplo, um cachorro, uma bicicleta, um aperto de mão ou mesmo as palavras e a linguagem - sendo esta um sistema de esquemas tipificados da experiência pré-linguística e sedimentada (Schutz e Luckmann, 1973, p. 233).

No entanto, toda esta dimensão estruturada do mundo-da-vida não se restringe às experiências e ações subjetivas do indivíduo. Para Schutz, a explicação da relação de um indivíduo com outro é parte fundamental da teoria sociológica. É através desta relação que é possível articularmos de maneira mais definida a própria possibilidade da sociologia, que seria a interpretação do outro.

Como vimos, a atitude natural é o modo pelo qual o indivíduo comum age no mundo-da-vida, isto é, de maneira familiar e autoevidente. Assim, da mesma maneira que a existência dos objetos e do mundo exterior lhe é dado desse modo, também a existência corpórea de outros indivíduos e de sua consciência o é. Esta atitude natural é, portanto, intersubjetiva (ou social), pois toma como óbvia a possibilidade de interagirmos com esses indivíduos e de sermos compreendidos por eles. Desse modo, ao interagirmos com o outro, diz Schutz, entramos em determinado tipo de relação com eles, que, na atitude natural, significa um espelhamento e uma reciprocidade de perspectivas: ambos os indivíduos compartilham uma mesma comunidade, podem viver experiências comuns e suas ações podem ser compreendidas como expressões de sua subjetividade (Schutz e Luckmann, 1973, p. 60 e 64).

Neste contexto, a comunicação linguística torna-se fundamental para a interação social, pois ela possibilita a transmissão de estruturas significativas típicas e de experiências vividas pelos indivíduos. Segundo Schutz, a linguagem é "a maior província de tipificações do mundo-da-vida" (Schutz e Luckmann, 1973, p. 234). As palavras, as gírias ou as expressões verbais cotidianas são frutos da sedimentação de experiências relevantes e típicas de toda uma sociedade. Ela possui, por isso, um caráter histórico, indicando o contexto da 
constituição dos tipos elaborados por várias gerações através da comunicação de experiências e ações intersubjetivas. Desse modo, por se originar deste contexto situacional e histórico do mundo-da-vida, ela é compreendida por Schutz como um "verdadeiro tesouro" de tipos e características pré-constituídos para a investigação do cientista (Schutz, 1953, p. 10).

Após a explicação deste breve panorama da fenomenologia de Schutz, podemos voltar à sua reelaboração do conceito de significado subjetivo, a fim de explicitar o objetivo da sociologia. Segundo o autor, o significado de uma ação pode se dar a partir de três perspectivas diferentes: (i) a do ator; (ii) a do indivíduo que interage socialmente com ele; e (iii) a do observador (cientista) que não se envolve nesta relação (Schutz, 1953, p. 19). Esta última perspectiva demonstra que o cientista, enquanto realiza seu trabalho, é o indivíduo que não participa da relação intersubjetiva entre os demais indivíduos, deixando de lado o jogo de espelhamentos de expectativas, compreensões e estados afetivos, pois ele passa a refletir sobre as estruturas do mundo-da-vida e, com isso, abandona a atitude natural cotidiana.

E, como vimos, a compreensão do significado da própria ação difere fundamentalmente da compreensão do significado da ação de indivíduos alheios. Por isso, ainda que o cientista não possa conhecer, de maneira imediata, os significados subjetivos dos indivíduos empíricos presentes na sociedade, ele pode, com base na observação desta, construir tipos teóricos, isto é, modelos de interação social no mundo-da-vida cotidiano que seguem trajetórias de ações racionais. ${ }^{3}$ Nos termos de Schutz, seriam fantoches, homúnculos, "empalhados" com um estoque de conhecimento e um sistema de tipicidade e relevância específicos para o estudo dos problemas pesquisados pelo cientista. A sociologia fenomenológica de Schutz tem como dados científicos, portanto, os esquemas de tipicidade e relevância e os estoques de conhecimento constituídos no mundo social pelos indivíduos. Porém, a sua formulação científica formaliza e generaliza esses dados até a construção de tipos teóricos ideais, passíveis de universalização. Nas palavras de Schutz, o modo de proceder da sociologia é o seguinte:

Em tal modelo simplificado do mundo social, atos puramente racionais, escolhas racionais a partir de motivos racionais são possíveis, porque todas as dificuldades que entravam o ator real no mundo-da-vida cotidiano foram eliminadas. Assim, o conceito

3 Simplificadamente, podemos afirmar que a construção teórica dos tipos baseia-se, entre outros, no postulado da racionalidade, isto é, os indivíduos tipificados devem ser construídos de tal maneira que agiriam da forma tipificada, caso tivessem conhecimento claro de todos os aspectos relevantes do cientista social (Schutz, 1953, p. 35). 
de racionalidade em sentido estrito, definido anteriormente, não se refere a ações dentro da experiência do senso-comum da vida cotidiana no mundo social; é a expressão de um tipo particular de construção de certos modelos específicos do mundo social feitos pelo cientista social para certas propostas metodológicas específicas (Schutz, 1953, p. 33).

\section{Considerações finais}

Após termos percorrido este breve panorama sobre a metodologia de pesquisa de Schütze e a sociologia fenomenológica de Schutz, resta-nos realizar uma comparação entre ambas as propostas teóricas.

Em relação à matriz teórica da sociologia, podemos perceber que as pretensões dos autores são bastante diferentes: Schutz quer elaborar uma nova matriz teórica para a sociologia, descrevendo, de maneira sistemática e minuciosa, uma filosofia do método das ciências sociais e as estruturas do mundo-da-vida que possibilitam o significado subjetivo. Já Schütze tem a intenção de elaborar uma metodologia de pesquisa capaz de produzir dados sociológicos específicos, ainda que seus conceitos estejam baseados em teorias sociológicas diferentes.

Em relação ao objeto sociológico, ambos os autores têm como escopo a explicação da realidade social a partir do significado subjetivo de ações e experiências. Porém, o modo como este significado subjetivo é elaborado pelo sujeito difere em ambos: ao passo que Schutz descreve toda uma dimensão do mundo-da-vida, em que o sujeito age de maneira autoevidente e óbvia, para apenas depois refletir sobre suas experiências, Schütze requer do sujeito a elaboração de uma narração biográfica global, tarefa esta bastante peculiar para qualquer indivíduo. Nesse sentido, Schütze busca no nível da linguagem narrada a descrição do significado subjetivo dado pelo indivíduo, ainda que este significado seja elaborado em contextos pré-linguísticos. Esta consequência é fruto de sua exigência a respeito dos dados científicos, que são elaborados apenas através das entrevistas com narrativas biográficas.

Por fim, em relação ao modo de proceder do método sociológico, encontramos algumas discrepâncias fundamentais entre os autores, o que acarretaria na maior dificuldade de aproximação entre ambos. Como vimos, o aparato filosófico e metodológico da sociologia fenomenológica de Schutz direciona-se à construção de tipos ideais, compostos a partir da formalização e generalização. Estes "fantoches", segundo o autor, têm a importância epistemológica de nos revelar, de maneira mais clara e determinada, os tipos de cursos de ação, baseados no princípio de racionalidade, e os esquemas de relevância e tipicidade constituídos por tipos de indivíduos na sociedade 
investigada pelo cientista. Nesse sentido, tais "fantoches" são sempre ideais e podem ser universalizados. ${ }^{4}$

Por outro lado, as pesquisas de Schütze não chegam a ser idealizadas e são muito mais específicas. Schütze não quer abordar tipos tão gerais e formais, como o carteiro, a empregada, o ciclista, etc. Ele restringe-se a campos cuja generalização é sempre limitada, como, por exemplo, seus estudos sobre Hülya, uma trabalhadora imigrante da Turquia que veio à Alemanha no período de 1972 (Schütze, 2006). Nesse sentido, o autor não realiza uma construção ideal e universal como pretende Schutz, mas realiza sempre uma interpretação do nível empírico de construção narrativa. Tudo aquilo que Schutz eliminou para a construção do tipo-ideal, "as dificuldades que entravam o ator real no mundo-da-vida cotidano", são incorporadas na análise da biografia e constituem o núcleo de seu trabalho. Ou seja, não haveria a possibilidade de pesquisa com narrativas biográficas (ou, pelo menos, elas não teriam um valor epistêmico tão grande) com um tipo-ideal schutziano, dado que este não enfrentou metamorfoses em sua vida e identidade, não passou por trajetórias de sofrimento ou por processos de criação de sua identidade biográfica.

Logo, podemos concluir que a sociologia fenomenológica não pode ser considerada a única matriz teórica que fundamenta a construção da metodologia de Schütze. Ainda que esta afirmação seja bastante óbvia, ela é realizada dentro de um questionamento bastante determinado: a pergunta pela fundamentação de uma teoria sociológica. Feita de maneira consistente, esta afirmação traz a vantagem, assim, de nos indicar um novo problema fundamental: se a pesquisa com narrativas biográficas reivindica uma concepção de sociologia própria, além de uma metodologia de pesquisa, como esta concepção poderia ser elaborada de maneira sistemática e consistente?

\section{Referências}

ELIAS, Norbert. Os alemães: a luta pelo poder e a evolução do habitus nos séculos XIX e XX. Trad.: Álvaro Cabral. Rio de Janeiro: Zahar, 1997.

ELLIOTT, Jane. Using narrative in social research: qualitative and quantitative approaches. London: Sage, 2005.

HO, Wing-Chung. Understanding the subjective point of view: methodological implications of the Schutz-Parsons Debate. Human Studies, n. 31, p. 383-397, 2008.

4 Uma visão crítica a respeito do método empregado por Schutz é encontrado em Thomas Wilson (2005), baseado na interpretação de que, apesar do contrário, o ponto de vista subjetivo do ator tem uma importância irrisória no modo de proceder da sociologia fenomenológica. Outro artigo que advoga na tese contrária e, por isso, pode ser considerado um bom contraponto é escrito por Wing-Chung Ho (2008). 
JOVCHELOVITCH, S.; BAUER, M. Entrevista narrativa. In: BAUER, M.; GASKELL, B. (Orgs.). Pesquisa qualitativa com texto, imagem e som: um manual prático. Trad.: Pedrinho A. Guareschi. 2. ed. Petrópolis: Vozes, 2003. p. 90-113.

ROSENTHAL, Gabriele. Biographical research. In: SILVERMAN, D.; SEALE, C. et al. (Orgs.). Qualitativa research practice. London: Sage, 2004. p. 48-64.

SCHUTZ, Alfred; LUCKMANN, Thomas. The structures of the life-world. Trad: R. Zaner e D. Parent. Northwestern University Press: Illinois, 1989. Vol. 2.

SCHUTZ, Alfred; LUCKMANN, Thomas. The structures of the life-world. Trad.: R. Zaner e H. T. Engelhardt. Illinois: Northwestern University Press, 1973. Vol. 1.

SCHUTZ, Alfred. The phenomenology of the social world. Trad.: G. Walsh e F. Lehnert. Illinois: Northwestern University Press, 1972.

. Common-sense and scientific interpretation of human action. Philosophy and Phenomenological Research, v. 14, n. 1, p. 1-3, Sept. 1953.

SCHÜTZE, Fritz. Biography analysis on the empirical base of autobiographical narratives: how to analyse autobiographical narrative interviews - part 1. Disponível em: <http://www.biographicalcounselling.com/download/B2.1.pdf>. Acesso em: 06 jul. 2010a.

. Biography analysis on the empirical base of autobiographical narratives: how to analyse autobiographical narrative interviews - part 2. Disponível em: $<$ http:// www.biographicalcounselling.com/download/B2.2.pdf>. Acesso em: 06 jul. 2010b.

. Hülya's migration to germany as self-sacrifice udergone and suffered in love for her parents, and her later biographical individualisation. Biographical problems and biographical work of marginalization and individualization of a young Turkish woman in germany. Historical social research, v. 31, n. 3, p. 107-126, 2006.

WELLER, Wivian. Tradições hermenêuticas e interacionistas na pesquisa qualitativa: a análise de narrativas segundo Fritz Schütze. Disponível em: $<$ http://www.anped.org. br/reunioes/32ra/arquivos/trabalhos/GT14-5656--Res.pdf > . Acesso em: 18 jan. 2011.

WILSON, Thomas. The problem of subjectivity in Schutz and Parsons. In: ENDRESS, M.; PSATHAS, G.; NASU, H. (Orgs.). Explorations of the life-world: continuing dialogues with Alfred Schutz. Springer: Dordrecth, 2005. 